\title{
Preface to the Special Issue: Managing Water Resources for a Sustainable Future
}

\author{
Luis Garrote $^{1} \cdot$ Alvaro Sordo-Ward ${ }^{1}$
}

Published online: 20 October 2020

(C) Springer Nature B.V. 2020

The 11th World Congress of the European Water Resources Association (EWRA) on Water Resources and Environment was held in Madrid, Spain, 24-29 June 2019, under the topic "Managing Water Resources for a Sustainable Future". The aim of the 11th Congress was to discuss innovation pathways in water resources management to address current and future challenges: growing uncertainty, greater extremes, increasing demand, water scarcity and global change. While traditional management practice is still effective, new technologies and approaches are emerging to better protect, regulate, allocate and recycle water resources. Sustainable management of water resources in the twenty-first Century requires a comprehensive understanding of the interaction of complex natural and social components in a changing context. The Congress was organized in eleven topical conferences, covering the full range of water resources management issues: (1) Hydroclimatic Extremes and Water Resources Management; (2) Water Quality and Water Treatment; (3) Hydrological Processes; (4) Urban Water Management; (5) Agricultural Water Management; (6) Water-Energy-Food Nexus; (7) Ecosystems and Environmental Processes; (8) Groundwater Hydrology, Contamination and Management; (9) Geoinformatics, Remote Sensing and Water Resources; (10) Global Change and Water Resources; and (11) Water Policy and Socioeconomic Issues.

The Congress was an open forum where scientists and engineers from diverse cultures around the world promoted environmentally sustainable water resources management and discussed their understanding of water resources systems at a diversity of scales. It was agreed to compile the most relevant communications in a special issue of Water Resources Management, with the title "Managing Water Resources for a Sustainable Future". The guest editors of this special issue selected 40 communications from among the 246 communications that appeared in the Congress proceedings in the form of extended abstracts. The selection was based on scientific quality and relevance for the journal, sending an invitation to submit a full manuscript to Water Resources Management. The 24 manuscripts that were submitted went

Luis Garrote

1.garrote@upm.es

Alvaro Sordo-Ward

alvaro.sordo.ward@upm.es

1 Department of Civil Engineering: Hydraulics, Energy and Environment, Universidad Politécnica de Madrid, Madrid, Spain 
through the strict review process of Water Resources Management, and 13 of them completed the review process in time to be included in this special issue. This issue is therefore a representation of scientifically sound and economically efficient solutions to current water management problems and is a valuable asset for scientists and practitioners.

By far the conference that attracted the largest number of contributions in the Congress was that devoted to hydroclimatic extremes. This special issue includes eight contributions on extreme events, focusing on droughts and floods. The first two articles refer to droughts and the other six articles cover topics ranging from extreme climate-driven processes linked to precipitation to flood risk assessments in rural/urban areas and the effects of climate change. The section starts with the contribution by Arnone et al. 2020, "Droughts prediction: a methodology based on climate seasonal forecasts", which proposes a methodology for drought assessment based on climate predictions of atmospheric variables, such as precipitation, temperature and wind speed, for upcoming season, up to seven months. The methodology integrates, through a statistical approach, seasonal forecast and reanalysis data to assess whether a region is under drought conditions, for predefined periods in the short future, at monthly scale. Application of the methodology to Zakynthos (Greece) and Sicily (Italy) showed promising findings, with satisfying matching between predictions and observations. The paper by Tigkas et al. 2020, "Implementing crop evapotranspiration in RDI for farm-level drought evaluation and adaptation under climate change conditions", deals with drought monitoring. They propose a new drought index, the Crop Reconnaissance Drought Index (CRDI) that is an adjustment of the well-known Reconnaissance Drought Index (RDI). They propose to substitute the reference evapotranspiration by crop evapotranspiration, thus focusing on drought impacts on a particular crop. The authors argue that the proposed index retains the advantages of RDI, but it is more suitable for devising farm level drought management plans, and they provide convincing arguments in their analysis of different crops in three regions of Greece.

The following two papers deal with the formulation of the intensity-duration-frequency (IDF) relations for extreme rainfall, both at local and regional scales, respectively. In their paper, "A robust method to update local river inundation maps using global climate model output and weather typing based statistical downscaling", Bermúdez et al. 2020, address the problem of the change of magnitude and frequency of extreme precipitation caused by the global warming. A robust method to update local IDF relations for sub-daily rainfall extremes using Global Climate Model (GCM) data is presented. Bonaccorso et al. 2020, in their study "Regional sub-hourly extreme rainfall estimates in Sicily under a scale invariance framework" address the problem of the design of urban drainage systems or flood risk assessment in small catchments, which often requires knowledge on n-minute rainfall events, but the data is unavailable or too scarce. Application to the Sicily region showed that regularities in the temporal pattern exhibited by storm records, known as scaling properties of rainfall, could help in characterizing extreme storms at partially gauged sites better than the application of traditional statistical techniques. In this study, a generalized extreme value (GEV) probability distribution simple scaling model was validated against sub-hourly historical observations at ten rain gauges, generally providing similar or better sub-hourly estimates than empirical approaches in relation to the scaling exponent value. Likewise, Soriano et al. 2020, analyze the effects of climate change on extreme peak flows in the paper "Quantification of expected changes in peak flow quantiles in climate change by combining continuous hydrological modelling with the modified Curve Number method". Application to four rural basins located in Spain show that the proposed methodology allows a better characterization of the response 
of catchments in flood events by considering the expected variation in the antecedent moisture content in the catchments.

Apart from the effect of climate change, changes in land cover also condition the flood risk of the territory. Recanatesi and Petroselli 2020, address this issue in their paper, entitled "Land cover change and flood risk in a peri-urban environment of the metropolitan area of Rome (Italy)". They analysed the land cover evolution (urban and industrial development) of the towns surrounding the city of Rome (Italy) and the consequential change of flood risk. Their methodology is based on the analysis of the information on land cover transformations, the identification of the occurred rainfall events and the application of combined hydrological and hydraulic modelling, to estimate the evolution of flooded areas and volumes. Zotou et al. 2020, conducted an analysis of the performance of the HEC-RAS hydraulic model while predicting the extent of the flooded area for a particular event in their paper "Using Sentinel-1 imagery to assess predictive performance of a hydraulic model". They used a threshold technique to delineate the flooded area from Sentinel-1 satellite imagery corresponding to an event in the Pineios river basin in Greece. They compared it to the prediction produced by the combination of HEC-HMS and HEC-RAS models, conducting several sensitivity analyses to characterize the sources of uncertainty. They conclude that satellite-based inundation mapping is a valuable tool to overcome lack of in-situ measurements while evaluating flood events with hydraulic models. Finally, on "Slackwater sediments record the increase in sub-daily rain flood due to climate change in a European Mediterranean catchment", Moral-Erencia et al. 2020, propose an original method to determine the magnitude of the discharge, the intensity of the precipitation and the duration of short-rain floods in small torrential basins. They studied areas that are located in ungauged catchments characterized by high erosion rates where torrents deposit slackwater sediments near the outlet of the basins. Such deposits and erosive morphologies allow to analyze sub-daily extreme hydrological events by combining standard techniques in paleohydrology, the kinematic wave method and remote-sensed paleostage indicators.

Espinosa and Portela 2020, in their paper "Rainfall trends over a small island teleconnected to the North Atlantic Oscillation - The Case of Madeira Island, Portugal", study long-term and recent rainfall trends over the small island of Madeira, located in the North Atlantic. They also conduct an exploratory analysis on the teleconnection of these trends with the North Atlantic Oscillation Index (NAOI). They present a detailed characterization of observed trends in the island using standard statistical tools and conclude that abrupt changes in the NAOI climatic driver can be directly linked to rainfall variability. They claim that their results are useful to improve water resources planning and management in the island.

Two methodological papers focus on the topic of decision analysis. In their paper " $A$ flexible approach for the reinforcement of water networks using Multi-Criteria Decision Analysis", Cunha et al. 2020, argue in favor of multicriteria decision analysis (MCDA) as a useful tool to select suitable interventions in urban water distribution networks to overcome problems created by insufficient hydraulic capacity. They propose a phased planning horizon scheme, where the foreseen reinforcements are periodically reassessed to adapt the projected designs as new information becomes available during the planning horizon. They demonstrate that their framework is able to account for four criteria to assess the performance of ten proposed interventions. They use a simple network to illustrate their methodology, but they claim that it includes most of the features that often characterize real networks. In their paper "A fuzzified multicriteria outranking method for Water Framework Directive implementation in a heavily modified urban lake (Pamvotis, Greece)", Spiliotis et al. 2020, also favor multicriteria analysis. They present a novel method to select the preferred alternative by 
applying six criteria following qualitative judgements from expert opinions. Their hybrid method consists on a combination of the outranking relation of the ELECTRE III method and the net flow of the PROMETHEE method. Their approach is based on the consideration of scores as fuzzy numbers to enable the interpretation of the criteria following fuzzy logic. Their case study, a heavily modified urban lake in Greece, illustrates how to approach environmental problems where the evaluation of alternatives is not straightforward.

The two concluding papers deal with water resources planning. On the paper "Comparing two hydro-economic approaches for multi-objective agricultural water resources planning", by Alamanos et al. 2020, the authors share their experience on the application of two hydroeconomic modelling approaches in a rural watershed located in Central Greece. Their focus is irrigated agriculture. They compared a simple and a detailed hydroeconomic model based on the assumptions, limitations, results, scope, accuracy and managerial implications. Their analysis provides useful insights on the most appropriate way to apply hydro-economic modeling, discussing how flexible the model settings should be and what would be the most appropriate approach. The paper by Pacetti et al. 2020, "Water values: participatory water ecosystem services assessment in the Arno River Basin, Italy", deals with the very interesting topic of Water-related Ecosystem Services (WES). The authors present a methodology for the participatory evaluation of WES. This effort is directly aligned with recent regulatory initiatives that enhance the right of stakeholders to participate in the decision-making process regarding water management. The authors successfully applied their methodology to the watershed planning process in the Arno River Basin, in Central Italy. They claim that their approach can be replicated at different scales and under various contexts leading to effective watershed management.

It has been a great honor for us to serve as guest editors for this special issue. The task would not have been possible without the contributions from many people. We wish to thank the journal Editor-in-Chief, Prof. George Tsakiris, for his commitment in ensuring the quality of this special issue, the referees for their time and effort in reviewing the papers and the authors for their contributions and their patience in dealing with the editorial processes. We would also like to thank all researchers, water managers and other experts who participated in the Congress for their inspiring input during three tiring days and to Universidad Politécnica de Madrid for hosting the event. Our gratitude also goes to Petra van Steenbergen and Mark Compendio, from the Springer editorial office, for their continuing guidance, support and help.

\section{References}

Alamanos A, Latinopoulos D, Loukas A, Mylopoulos N (2020) Comparing two hydro-economic approaches for multi-objective agricultural water resources planning. Water Resour Manag. https://doi.org/10.1007/s11269020-02690-6

Arnone E, Cucchi M, Dal Gesso S, Petitta M, Calmanti S (2020) Droughts prediction: a methodology based on climate seasonal forecasts. Water Resour Manag. https://doi.org/10.1007/s11269-020-02623-3

Bermúdez M, Cea L, Van Uytven E, Willems P, Farfán JF, Puertas J (2020) A robust method to update local river inundation maps using global climate model output and weather typing based statistical downscaling. Water Resour Manag. https://doi.org/10.1007/s11269-020-02673-7

Bonaccorso B, Brigandi G, Aronica G (2020) Regional sub-hourly extreme rainfall estimates in Sicily under a scale invariance framework. Water Resour Manag. https://doi.org/10.1007/s11269-020-02667-5

Cunha MC, Marques J, Savić D (2020) A flexible approach for the reinforcement of water networks using multicriteria decision analysis. Water Resour Manag. https://doi.org/10.1007/s11269-020-02655-9 
Espinosa LA, Portela MM (2020) Rainfall trends over a small island teleconnected to the North Atlantic oscillation - the case of Madeira Island, Portugal. Water Resour Manag. https://doi.org/10.1007/s11269020-02668-4

Moral-Erencia JD, Bohorquez P, Jimenez-Ruiz PJ, Pérez-Latorre FJ (2020) Slackwater sediments record the increase in sub-daily rain flood due to climate change in an European Mediterranean catchment. Water Resour Manag. https://doi.org/10.1007/s11269-020-02563-y

Pacetti T, Castelli G, Bresci E, Caporali E (2020) Water values: participatory water ecosystem services assessment in the Arno River basin, Italy. Water Resour Manag. https://doi.org/10.1007/s11269-02002684-4

Recanatesi F, Petroselli A (2020) Land cover change and flood risk in a peri-urban environment of the metropolitan area of Rome (Italy). Water Resour Manag. https://doi.org/10.1007/s11269-020-02567-8

Soriano E, Mediero L, Garijo C (2020) Quantification of expected changes in peak flow quantiles in climate change by combining continuous hydrological modelling with the modified curve number method. Water Resour Manag. https://doi.org/10.1007/s11269-020-02670-w

Spiliotis M, Panagiotou L, Kagalou I, Latinopoulos D (2020) A fuzzified multicriteria outranking method for water framework directive implementation in a heavily modified urban lake (Pamvotis, Greece). Water Resour Manag. https://doi.org/10.1007/s11269-020-02624-2

Tigkas D, Vangelis H, Tsakiris G (2020) Implementing crop evapotranspiration in RDI for farm-level drought evaluation and adaptation under climate change conditions. Water Resour Manag. https://doi.org/10.1007 /s11269-020-02593-6

Zotou I, Bellos V, Gkouma A, Karathanassi V, Tsihrintzis VA (2020) Using Sentinel-1 imagery to assess predictive performance of a hydraulic model. Water Resour Manag. https://doi.org/10.1007/s11269-02002592-7

Publisher's Note Springer Nature remains neutral with regard to jurisdictional claims in published maps and institutional affiliations. 